\section{$\underset{\substack{\text { hommes } \\ \text { \& migrations }}}{ }$}

\section{Hommes \& migrations}

Revue française de référence sur les dynamiques

migratoires

$1310 \mid 2015$

Fashion Mix

\title{
Sylvain Pattieu, Beauté Parade
}

Plein Jour éditions, 2015, 14 pages, $18 €$

\section{Mustapha Harzoune}

\section{(2) OpenEdition}

\section{Journals}

Édition électronique

URL : http://journals.openedition.org/hommesmigrations/3207

DOI : 10.4000/hommesmigrations.3207

ISSN : 2262-3353

Éditeur

Musée national de l'histoire de l'immigration

\section{Édition imprimée}

Date de publication : 1 avril 2015

Pagination : 192-193

ISBN : 978-2-919040-31-5

ISSN : 1142-852X

\section{Référence électronique}

Mustapha Harzoune, «Sylvain Pattieu, Beauté Parade», Hommes \& migrations [En ligne], 1310 | 2015,

mis en ligne le 17 décembre 2015, consulté le 24 septembre 2020. URL : http://

journals.openedition.org/hommesmigrations/3207; DOI : https://doi.org/10.4000/

hommesmigrations.3207 


\section{LIVRES}

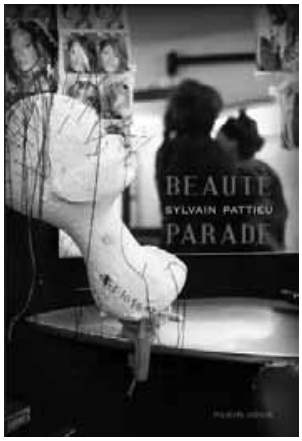

\section{Sylvain Pattieu} Beauté Parade

Plein Jour éd., 2015, 214 pages, 18 euros

Sylvain Pattieu récidive avec un genre et une écriture qui bousculent le ronron. À cheval entre enquête journalistique, recueil de témoignages, étude sociologique et...

littérature. Car ce texte a du style, des tensions et des personnages, du neuf et de l'évasion, l'ébranlement et le brasier de la poésie.Après le quotidien d'Alima et Bintou, deux lycéennes de Seine-SaintDenis (Les Impatientes, La Brune, 2012), après les mobilisations des ouvriers d'Aulnay (Avant de disparaitre. Chronique de PSA-Aulnay, Plein Jour, 2013) Sylvain Pattieu pousse ici la porte d'un salon de beauté sis au 50 boulevard destrasbourg dans ce $X^{\mathrm{e}}$ arrondissement de Paris où "tout n'est pas encore joué. Tout n'est pas lisse, pas homogène". Ici, les employées, africaines et asiatiques, spécialisées qui en onglerie qui en coiffure, sont pour la plupart sans papiers - "engagées volontaires, mais choisit-on vraiment, quand on vient du mauvais côté du monde?". Elles ont décidé d'occuper les lieux. De revendiquer le droit à un peu de dignité et de liberté. Être payé, c'est le minimum, non! Être régularisé. En finir avec les faux-semblants et "les contradictions du système" : "ll y a un marché du travail qui n'est pas seulement hexagonal", qui prospère sans appauvrir les salariés nationaux, mais en surexploitant le lumpen prolétariat des temps modernes. La mobilisation va durer soixante-quinze jours. Sylvain Pattieu est aux côtés de ces femmes. II raconte, s'efface et laisse parler. Donne à entendre. Page après page, s'esquissent les portraits de Lin Mei, Fengzhen, Yanping, Souqin, Madissou et Adja. Six femmes et un homme, Gang. L'Afrique et l'Asie. Six femmes et un homme partis en lutte comme on embarquerait sur un rafiot de fortune sans savoir si l'on accostera jamais. Le lecteur finit par côtoyer des êtres, de chair et de sang, de rires et de larmes, de solidarité et de doute. Existences livrées en fragments, "paroles singulières" qui se glissent entre les chapitres et descriptions de l'auteur.

Sylvain Pattieu raconte le quotidien et l'intime de cette lutte, les soutiens, membres de la CGT, les intimidations et les pressions exercées par les autres patrons de salons de beauté, les procédures à suivre face aux tergiversations et aux manigances de la Préfecture. Paris a changé. Sous ses ponts l'eau a coulé depuis belle lurette. Frédéric Ciriez (Mélo, Verticales, 2013) en donnait un aperçu. Sylvain Pattieu poursuit : "Il n'y a plus d'industrie à Paris. Mais il y a des services, des boulangers qui mitonnent, des ouvriers qui bâtissent et rénovent, des balayeurs qui nettoient, des vendeurs qui conseillent, des manutentionnaires et des livreurs qui placent, des serveurs qui prennent la commande, des caissières qui encaissent, des conducteurs de métro, de bus, de tramway, de RER, des intérimaires qui font la queue, des nounous qui jouent et qui grondent. Il y a des petites mains qui s'affairent sur les têtes et sur les mains. Moins de bruit, moins de syndicats, mais elles sont là." "l aurait pu, avec Gauz (Debout-payé, Le Nouvel Attila, 2014), ajouter les "grosses" 
mains des vigiles. L'immigration aussi a changé. Elle n'est plus une affaire d'hommes. Les femmes, plus nombreuses, ne se cantonnent plus dans un foyer synonyme parfois de prison. Elles sortent, se déplacent, travaillent, assument des responsabilités, deviennent

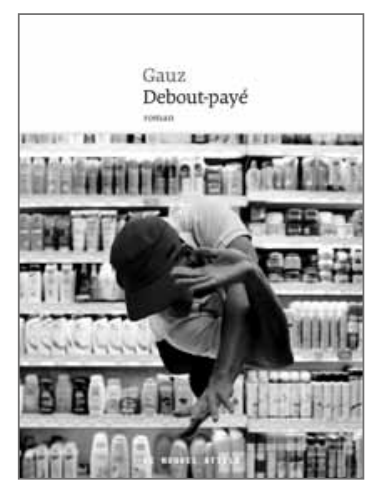

\section{Gauz \\ Debout-payé}

Le Nouvel Attila, 2014, 175 pages, 17 euros.

Debout-payé, on le sait maintenant, parle des vigiles. Ce vigile mystérieux et lointain témoin de nos errances commerciales. Les gros bras de l'immigration délaissent le marteau-piqueur pour mieux impressionner le chaland. Vigile, ce n'est pas une sinécure. Juste une galère quand on est sans le sou et maigrichon en docs administratifs. Des jours entiers à rester debout. À s'ennuyer. À se péter la vessie. $\grave{A}$ se polluer le tympan des musiques d'ambiance. Le vigile observe. Scrute. Pythonisse. Gauz glisse, sous forme de chapitres, les pensées, anecdotes, aphorismes, observations du vigile en poste à Sephora-Champs-Élysées ou à Camaïeu Bastille. Et comme la marge possède quelques infos que le centre ignore, il faut écouter ce que ces debout-payés disent d'une ville et de ses populations, socialement diverses et culturellement métissées. Après Mélo de Ciriez et avant Beauté parade de Sylvain Pat- même de véritables "chefs" de famille. Elles se mobilisent et luttent. Beauté Parade montre ces "femmes métamorphes" qui "obtiennent ou acquièrent la liberté de mouvement, du corps et de l'esprit".

Mustapha Harzoune

tieu, ce Debout-payé offre l'opportunité de découvrir, sous un angle inhabituel, Paris, ses transformations et un peu de son devenir.

Ces réflexions in petto du vigile, de valeur inégale, mais souvent drôles et incisives, se glissent entre le récit, sur deux générations de l'immigration ivoirienne. Il y a les lieux, à commencer par la Maison des étudiants de Côte d'Ivoire. Il y a les personnages. Ainsi ce Ferdinand qui reçoit ses jeunes compatriotes en leur servant un menu dans la pure tradition française, jusqu'au camembert "qui pue"! Si ce n'est pas un signe de proximité culturelle! On pense au steak tartare de Faïza Guène. Les plus jeunes, en coloc du côté de Bastille, se prénomment Kassoum et Ossiri.

L'originalité de ce premier roman tient aux étincelles d'une langue bigarrée, au style iconoclaste, impertinent, provocateur. L'esprit corrosif enraye le ronron des mécaniques trop bien huilées. Parmi les passages savoureux, il y a ces clefs fournies pour identifier la nationalité des Africains par leur tenue vestimentaire ou par leur accent. Aux obsèques de Pompidou, les larmes de Bokassa ler sont à se tordre! Pour mémoire, il est bon de revenir à 1974, l'année où "nos" politiques, droite et gauche confondues, 